\title{
Study Of Cutting Edge Temperature And Cutting Force Of End Mill Tool In High Speed Machining
}

\author{
Mohammad Ashaari Kiprawi ${ }^{1}$, Abdullah Yassin ${ }^{1 . a}$, Syed Tarmizi Syed Shazali ${ }^{1}$, M. Shahidul Islam ${ }^{1}$ and Mohd Azrin Mohd \\ Said ${ }^{1}$ \\ ${ }^{1}$ Department of Mechanical and Manufacturing Engineering, Faculty of Engineering, Universiti Malaysia Sarawak (UNIMAS), Malaysia
}

\begin{abstract}
A wear of cutting tools during machining process is unavoidable due to the presence of frictional forces during removing process of unwanted material of workpiece. It is unavoidable but can be controlled at slower rate if the cutting speed is fixed at certain point in order to achieve optimum cutting conditions. The wear of cutting tools is closely related with the thermal deformations that occurred between the frictional contact point of cutting edge of cutting tool and workpiece. This research paper is focused on determinations of relationship among cutting temperature, cutting speed, cutting forces and radial depth of cutting parameters. The cutting temperature is determined by using the Indium Arsenide (InAs) and Indium Antimonide (InSb) photocells to measure infrared radiation that are emitted from cutting tools and cutting forces is determined by using dynamometer. The high speed machining process is done by end milling the outer surface of carbon steel. The signal from the photocell is digitally visualized in the digital oscilloscope. Based on the results, the cutting temperature increased as the radial depth and cutting speed increased. The cutting forces increased when radial depth increased but decreased when cutting speed is increased. The setup for calibration and discussion of the experiment will be explained in this paper.
\end{abstract}

\section{Introduction}

One of the important process in manufacturing a metal product is machining process. The purpose of the process is to remove unwanted material from the workpiece to obtain a desired shape and high dimension accuracy of the parts or products. The precision of the surface finishing normally used a high speed machining process in order to increase consistency of surface's integrity. There are drawbacks when machining process is done in high speed. It affects the cutting edge of tool's bit, the workpiece surface integrity, chip formation mechanism, and contribute to the thermal deformation of the cutting tool [1]. This is due to the nature of friction energy accumulates at the contact point of workpiece and cutting edge of tool's bit. The friction resisting overtime and dissipates as thermal energy. This phenomenon has thermally weaken the mechanical strength of workpiece, and cutting tools. The degree of friction is associated with the cutting speed. It is important to determine the cutting temperature to study the performance cutting tools at particular cutting speed.

Several extensive studies on milling temperatures have been conducted. Sato et al. [2] have studied the temperature and force variation existed during milling process of titanium alloy Ti-6Al-4V. They showed that the cutting temperature gradient is higher when down milling compared to up milling. Richardson et al.[3] have conducted a research to study the effects of high cutting speed to workpiece temperature. He found that the workpiece temperature decrease when cutting speed is increase at extreme rate. This finding was supported by Ye et.al. [1] as they found that increasing cutting speed will reduce finished surface temperature but increasing tool-chip contact temperature. Ueda et al. [5] have found that the cutting tool temperature of cemented carbide insert increase proportionally when the cutting speed increase. They also find the similar trend when the radial depth of cut increases. Interesting studies have been done by Komanduri et al [6] as they have determined the distribution of temperature in the chip, the tool, and the work material by using functional analysis approach. The analytical solution is based on the temperature rise distribution due to shear plane heat source in metal cutting.

The existence of wear in cutting tools is due to the presence of stress during cutting process. Tang et al. [7] have found the correlation between wear and cutting forces. As the cutting forces increases, the flank wear will also increase. This study is further studied by Ma et al. [8] as they have simplified analytical model of the cutting loads and stress zone during cutting process. Ma et al. [9] used a Finite Element Method (FEM) model and showed that initial tensile stress makes the cutting stress distribution within the workpiece become more tensile and diminishes the cutting forces and tool tip temperature.

\footnotetext{
a Corresponding author: yabdulla@unimas.my
} 
Infrared waves radiated from the cutting edge of cutting tools can be utilized to study the cutting performance of the cutting process. Therefore, application of optical fibre pyrometer was developed and studied to enable flexible position in temperature measurement.

\section{Experimental}

A vertical machining center was used as a milling machine for the experiment. Workpiece was made of carbon steel. $6 \mathrm{~mm}$ carbide flute solid end mill cutter was used. The cutting edge temperature of cutting tool was measured using a pyrometer with an optical fibre. The cutting force was measured using a dynamometer. The experiment was divided to cutting temperature, cutting force measurement, and calibration of pyrometer.

\subsection{Pyrometer Calibration}

Calibration of the pyrometer was needed in order to obtain the calibration curve. The function of calibration curve was to relate the voltage output from the photocell to its corresponding temperature. The calibration curve equation was then used in the cutting temperature measurement of cutting process. The radiated infrared waves from the heated carbide cutting tool was detected with photocell. The data of calibration was started from higher to lower temperature. Thermocouple was used in the calibration process to monitor the temperature of heated cutting tools. Amplifier was fixed at constant scale throughout calibration and experiment to maintain accuracy, consistency and reliability of data acquisition. The calibration setup of pyrometer was illustrated as in Figure 1.

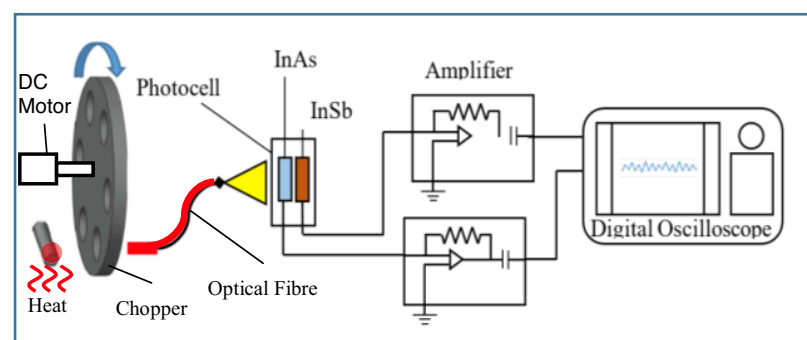

Figure 1 Test Rig Schematic Design for Temperature Calibration

\subsection{Cutting edge temperature and cutting force measurement}

An infrared radiation was emitted at the cutting edge of cutting tools. The photocell captured the infrared waves and convert it to voltage output using amplifier. Digital oscilloscope visualized the voltage signal in waves form. The cutting force from the cutting process was obtained from the dynamometer. The recorded value of voltage was then substituted to the calibration curve equation to get a correspond temperature. The experiment was conducted by comparing cutting speeds and cutting depths with respect to its cutting temperature and cutting force respectively. The experimental setup was shown in Fig. 2.

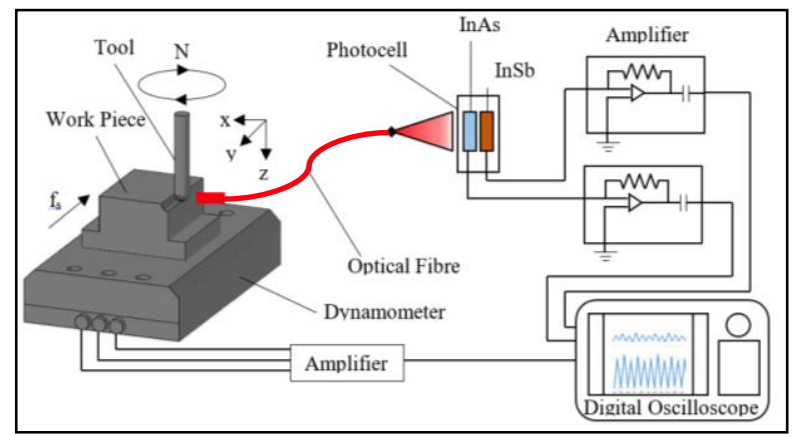

Figure 2 Experimental Setup Schematic Design

\section{Results and discussion}

\subsection{Calibration curve}

The voltage output from the pyrometer was recorded by digital oscilloscope. The calibration curve was obtained by finding the relationship of the ratio of InAs's voltage output to InSb's voltage output with its correspond temperature reading acquired from the thermo-couple as stated in Table 1. The calibration curve was shown in Figure 3.

Table 1 Calibration Data of Pyrometer

\begin{tabular}{|c|c|c|c|}
\hline $\begin{array}{c}\text { Average } \\
\text { temperatrature } \\
\left({ }^{\circ} \mathrm{C}\right)\end{array}$ & InAs $(\mathrm{V})$ & InSb $(\mathrm{V})$ & InAs/InSb \\
\hline 314.40 & 49.9370 & 0.3112 & 160.4659 \\
\hline 286.80 & 39.5330 & 0.2800 & 141.1893 \\
\hline 279.15 & 29.8500 & 0.2743 & 108.8106 \\
\hline 267.05 & 23.5830 & 0.2697 & 87.4513 \\
\hline 254.95 & 18.6170 & 0.2667 & 69.8129 \\
\hline 242.75 & 15.6500 & 0.2640 & 59.2803 \\
\hline 231.00 & 13.3670 & 0.2623 & 50.9549 \\
\hline 219.50 & 11.8000 & 0.2853 & 41.3556 \\
\hline 203.60 & 10.7000 & 0.2593 & 41.2602 \\
\hline 198.50 & 9.8167 & 0.2580 & 38.0492 \\
\hline 188.45 & 9.2000 & 0.2573 & 35.7518 \\
\hline 178.65 & 8.7167 & 0.2557 & 34.0936 \\
\hline 170.20 & 8.4167 & 0.2557 & 32.9202 \\
\hline 162.05 & 8.1167 & 0.2543 & 31.9140 \\
\hline 155.05 & 7.8667 & 0.2537 & 31.0116 \\
\hline 157.20 & 7.7167 & 0.2543 & 30.3413 \\
\hline 142.80 & 7.6167 & 0.2533 & 30.0663 \\
\hline
\end{tabular}




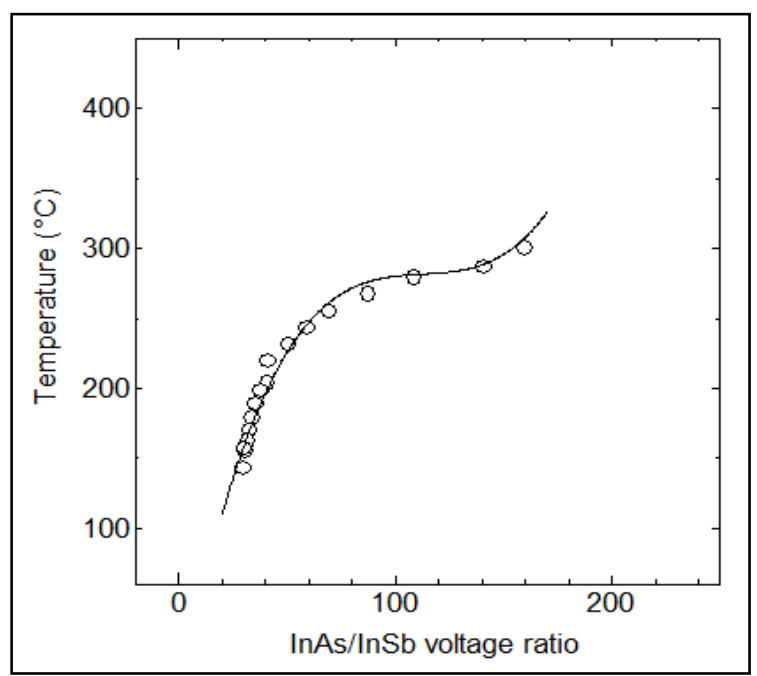

Figure 3 Calibration curve of InAsInSb pyrometer

\subsection{Calibration equation}

Calibration equation was developed from the calibration curve with NGraph software. The calibration equation was

$$
\mathrm{y}=-23.18+7.957 x-0.07 x^{2}+\left(2.0 \times 10^{-4}\right) x^{3}
$$

Where,

$$
\begin{aligned}
& \mathrm{y}=\text { corresponding temperature } \\
& \mathrm{x}=\text { InAs-InSb ratio }
\end{aligned}
$$

\subsection{Cutting temperature of end mill tool}

In Figure 2, data acquisition process was recorded by using digital oscilloscope. Sample data of cutting edge temperature was shown in Figure 4.

Two sets of cutting parameters were chosen for cutting edge temperature measurement and cutting force measurement as stated in table 2 and table 3 respectively.

The peak shown in Figure 4 resembles the contact occurrences between cutting edge of cutting tools and workpiece. The peaks were produced due to friction between contact point of end mill's tooth and workpiece's surface, formation of chip, and the wear of cutting tools itself. As mechanical friction incites heat, infrared waves' peak were generated from it. In the graph, it shows that the cycle for one complete revolution of cut was 0.002 seconds.

Table 2 Cutting parameters for cutting temperature experiment

\begin{tabular}{|c|c|}
\hline Cutting parameter & Value \\
\hline Tool diameter, $\varnothing$ & $6 \mathrm{~mm}$ \\
\hline Tool revolution (RPM) & $\begin{array}{l}10000,15000,20000 \\
25000,30000,35000\end{array}$ \\
\hline Cutting speed (m/min) & $188,283,377,471,565,660$ \\
\hline Feed rate $(\mathrm{mm} / \mathrm{min})$ & $\begin{array}{c}300,450,600,750,900 \\
1050\end{array}$ \\
\hline $\begin{array}{l}\text { Y-axis radial depth of cut, } R_{d} \\
(\mathrm{~mm})\end{array}$ & $0.5,1.0,1.5,2.0$ \\
\hline $\begin{array}{l}\text { X-axis axial depth of cut, } A_{d} \\
(\mathrm{~mm})\end{array}$ & 1.0 \\
\hline
\end{tabular}

\begin{tabular}{|c|c|}
\hline Cutting parameter & Value \\
\hline Tool diameter, $\varnothing$ & $6 \mathrm{~mm}$ \\
\hline Tool revolution $(\mathrm{RPM})$ & $10000,20000,30000,40000$ \\
\hline Cutting speed $(\mathrm{m} / \mathrm{min})$ & $188,377,565,754$ \\
\hline Feed rate $(\mathrm{mm} / \mathrm{min})$ & $300,600,900,1200$ \\
\hline $\begin{array}{c}\text { Y-axis radial depth of cut, } \mathrm{R}_{\mathrm{d}} \\
(\mathrm{mm})\end{array}$ & $1.0,2.0,3.0$ \\
\hline $\begin{array}{c}\mathrm{X} \text {-axis axial depth of cut, } \mathrm{A}_{\mathrm{d}} \\
(\mathrm{mm})\end{array}$ & 1.0 \\
\hline
\end{tabular}

Table 3 Cutting parameters for cutting force experiment

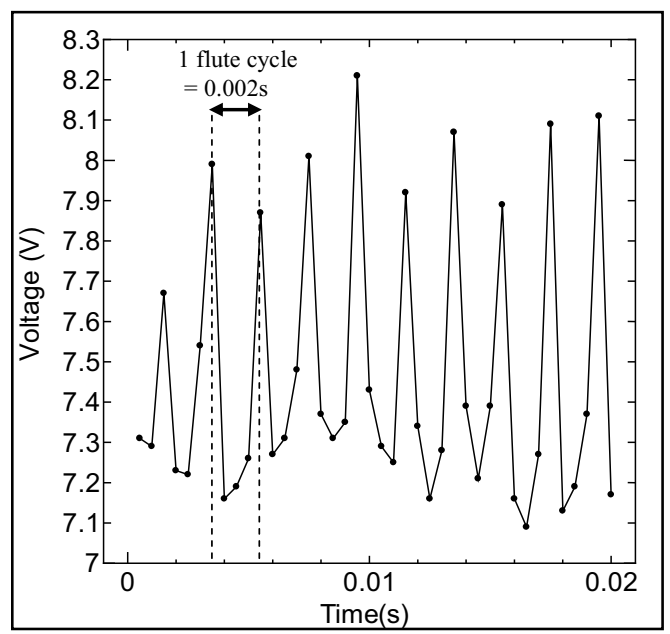

Figure 4 Sample of InAs voltage output from cutting edge temperature obtained from digital oscilloscope (30,000 RPM)

\subsection{Effects of different cutting speed and radial depth}

There were relationship found between cutting speed cutting edge temperature, and cutting forces. The relationship was shown in the figure 5 and 6 . It was clear that the cutting speed and radial depth affects the cutting edge temperature and cutting force.

Figure 7 revealed that a significant temperature rise of $17 \%$ can be seen as Rd is increased from $1 \mathrm{~mm}$ to $2 \mathrm{~mm}$ at cutting speed of $188 \mathrm{~m} / \mathrm{min}$. The temperature change was not very apparent when Rd was set to $3 \mathrm{~mm}$ which is an increase of only $6 \%$. This was the result of time delay between each cut which gives extra time for the heat energy from the cutting tool to spread to the surrounding. The same case can be seen for cutting speed at 754 $\mathrm{m} / \mathrm{min}$ which shows an increase of $18 \%$ when $\mathrm{Rd}$ was increased from $1 \mathrm{~mm}$ to $2 \mathrm{~mm}$ but when Rd was further increased to $3 \mathrm{~mm}$, an increase of only $6 \%$ can be seen. The result of the experiment was supported the theory postulated by Trajcevski [10].

The increase in temperature when radial depth of cut was increased due to the higher plastic deformation which occurs at the primary and secondary deformation zone. According to Trent and Wright, heat was produced as a result of the combined shear and friction action from the sticking and sliding friction sections [11]. The rise in 
temperature also occurs at the tertiary deformation zone as a result of work done in overcoming frictional force at the rubbing contact between the tool flank face and the newly machined surface of the work piece.

From Figure 8, the cutting temperature increased significantly as the cutting speed increase when Ad and Rd were kept constant. Generally, a higher cutting speed accelerates the generation of cutting temperature. This is the result of the less time available for the heat generated to conduct into the work piece [12].

For $\mathrm{Rd}=1 \mathrm{~mm}$, cutting temperature increased by $18 \%$ when cutting speed was increased from $188 \mathrm{~m} / \mathrm{min}$ to 377 $\mathrm{m} / \mathrm{min}$. Furthermore, it can be seen that when cutting speed was further increased to $565 \mathrm{~m} / \mathrm{min}$, the rise in temperature was much slower when an increase of only $10 \%$ was seen. Lastly, cutting temperature rose by only $5 \%$ when cutting speed was increased to $754 \mathrm{~m} / \mathrm{min}$. This trend was quite similar for every radial depth of cut. It agrees to hypothesis by Salomon who discussed that the cutting temperature decreases with increasing the cutting speed after it attains a peak for a certain critical value [13].

For cutting forces at cutting speed variation shown in Figure 6, it can be concluded that cutting force will decreases in increasing rotational speed for all four different radial depth of cut. The larger the radial depth of cut, the higher the overall cutting force Fy. Thermal effects could be a significant cause for the peak force variation within a single cutting pass. As the rotational speed increase, the temperature in the cutting toolworkpiece interface will increase. These increase in temperature will resulted in softening of the workpiece, thus less friction and shear forces are needed to remove the material from the workpiece. Hence, the cutting forces will decreases.

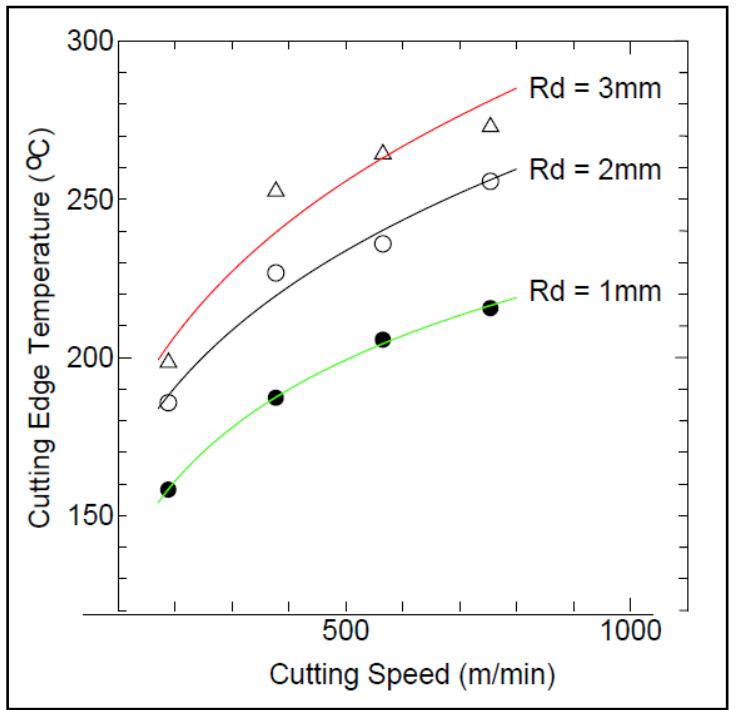

Figure 5 Cutting edge temperature increase as the cutting speed increase

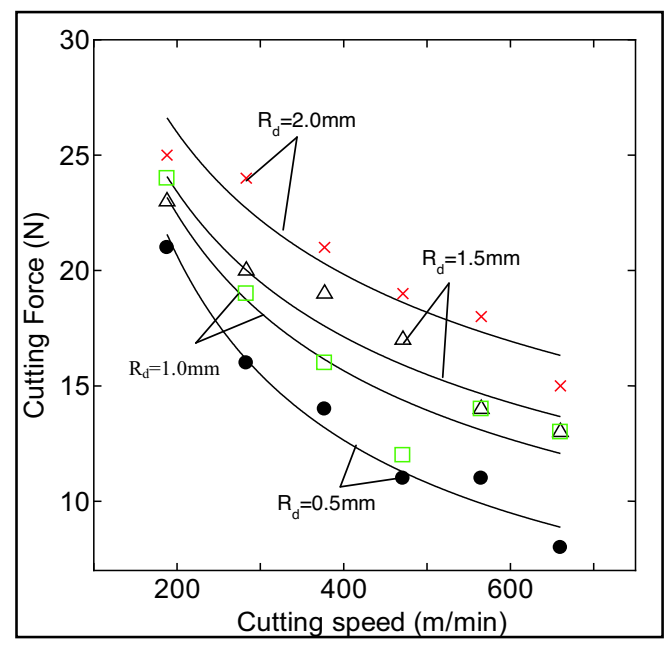

Figure 6 Cutting force decrease as the cutting speed

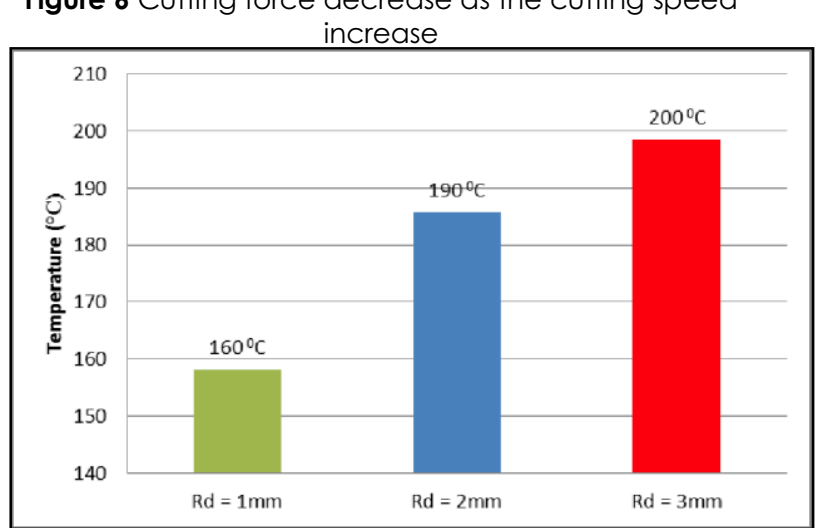

Figure 7 Cutting temperature at $188 \mathrm{~m} / \mathrm{min}$ for different radial depth of cut, $\mathrm{Rd}$.

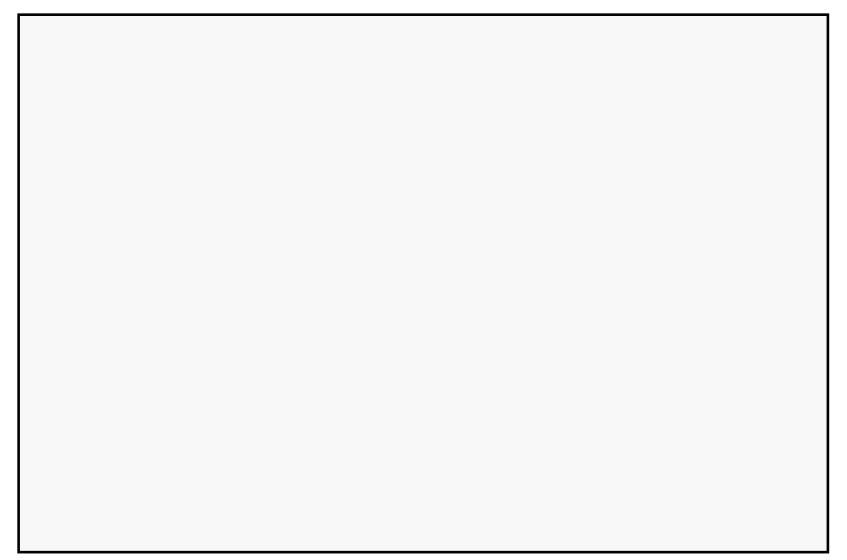

Figure 8 Cutting temperature at $R_{d}=1 \mathrm{~mm}$ for different cutting speed.

\section{Conclusions}

From the experiment, it can be concluded that an increase in radial depth of cut accelerates the generation of heat, thus causing an increase in cutting temperature. This was due to the increase in plastic deformation at primary and secondary deformation zone. Furthermore, the work done in overcoming frictional force in tertiary deformation zone was also a contributing factor. Secondly, it can be seen that from the experiment, the cutting temperature increase as cutting speed was increased. While cutting forces shows inverse trend when increasing the cutting 
speed. A higher cutting speed provides less time for heat energy generated to be conducted to the work piece. Heat energy are then forced to stay in the cutting tool, thus increasing its temperature while reducing the friction surface contact.

The pyrometer that had been developed are functioning as intended and proves that the emission of infrared radiation can be harnessed by using flexible optical fibre and photocell to measure cutting edge temperature during high speed machining.

\section{Acknowledgement}

Authors are grateful for the UNIMAS Exploratory Research Grant Scheme: ERGS/TK01(01)/1007/2013 (04) for giving a fund assistance to equip the laboratory with appropriate tools and devices to conduct this project.

\section{References}

1. N. A. Abukhshim, P. T. Mativenga, and M. A. Sheikh. 2006. Heat generation and temperature prediction in metal cutting: A review and implications for high speed machining. Int. J. Mach. Tools Manuf., vol. 46, no. 7-8, 782800 .

2. M. Sato, N. Tamura, and H. Tanaka. 2011. Temperature Variation in the Cutting Tool in End Milling. J. Manuf. Sci. Eng., vol. 133, no. 2, p. 021005 .

3. H. Schulz. 1999. The History of High-Speed Machining. Rev. Ciência e Tecnol. : 9-18.

4. G. G. Ye, S. F. Xue, W. Ma, M. Q. Jiang, Z. Ling, X. H. Tong, and L. H. Dai. 2012. Cutting AISI 1045 steel at very high speeds. Int. J. Mach. Tools Manuf., vol. 56: 1-9.

5. T. Ueda, A. Hosokawa, K. Oda, and K. Yamada. 2001. Temperature on Flank Face of Cutting Tool in High Speed Milling. CIRP Ann. - Manuf. Technol., vol. 50, no. 1: 37-40.

6. R. Komanduri and Z. B. Hou. 2001. Tribology in Metal Cutting-Some Thermal Issues. J. Tribol., vol. 123, no. October:: 799.

7. Z. T. Tang, Z. Q. Liu, Y. Z. Pan, Y. Wan, and X. Ai. 2009. The influence of tool flank wear on residual stresses induced by milling aluminum alloy. J. Mater. Process. Technol., vol. 209, no. 9: 4502-4508.

8. Y. Ma, P. Feng, J. Zhang, Z. Wu, and D. Yu. 2016 Prediction of surface residual stress after end milling based on cutting force and temperature. J. Mater. Process. Technol., vol. 235: 41-48.

9. Y. Ma, D. Yu, P. Feng, Z. Wu, and J. Zhang. 2015. Finite element method study on the influence of initial stress on machining process. Adv. Mech. Eng., vol. 7, no. 3: 0-10.

10. N. Trajcevski, M. Kuzinovski, and P. Cichosz. 2009. Investigation of temperature during machining process by high speed turning: 3-6.
11. E. M. Trent and P. K. Wright, Metal Cutting. 2000. 4th Editio. Boston, MA: ButterworthHeineman.

12. G. Ye, S. Xue, X. Tong, and L. Dai. 2011. Influence of cutting conditions on the cutting performance of TiAl6V4. vol. 337: 387-391.

13. J. M. Longbottom and J. D. Lanham. 2006. A review of research related to Salomon's hypothesis on cutting speeds and temperatures. Int. J. Mach. Tools Manuf., vol. 46, no. 14: 1740-1747. 